Available online at GSC Online Press Directory

GSC Biological and Pharmaceutical Sciences

e-ISSN: 2581-3250, CODEN (USA): GBPSC2

Journal homepage: https://www.gsconlinepress.com/journals/gscbps

(REVIEW ARTICle)

\title{
A review study of waterborne parasites in Iraq
}

\author{
Hadi Hind *, Hadi Afkar and Jassim Suhad \\ Iraq Natural History Research Center and Museum, University of Baghdad, Baghdad, Iraq
}

Publication history: Received on 04 February 2020; revised on 08 March 2020; accepted on 09 March 2020

Article DOI: https://doi.org/10.30574/gscbps.2020.10.3.0031

\begin{abstract}
Waterborne parasites are primary parasites that are ubiquitous and affect humans, pets, and wildlife throughout the world. According to the World Health Organization, more than 80 human diseases transmitted by water in developing countries, $60 \%$ of the population do not have access to clean drinking water .Waterborne diseases occur worldwide, and outbreaks caused by the contamination of community water systems have the potential to cause disease in large number of consumers. This study dealt with the database of studies of waterborne parasites in Iraq. Which includes the following classes of parasites: Nematodes as Ascaris lumbericoides, Trichuris sp., Strongyloides stericorailis and Enterobius vermicularis. Cestodes as Taenia sp. and Hymenolips nana. Trematodes as Fasciola sp. and Schistosoma haematobium. Protozoa as Entamoeba histolytica, Trichomonus vaginalis, Chilomastix sp., Iodamoeba butschlii, Naegleriae sp., Coccidia sp., Acanthamoeba sp., Cryptosporidium parvum, Cryptosporidium muris, Giardia lamblia, Blantidium sp., and Entamoeba coli.
\end{abstract}

Keywords: Water born; Entamoeba histolytica; Giardia lamblia; Ascaris lumbricoides; Iraq

\section{Introduction}

Water is the main ingredient on earth It is vital to all known life forms, and It is an essential nutrient for proper maintenance of homeostasis in the human body. It exists in liquid, solid, and gaseous state [1]. Water is used for more than drinking, it is used for swimming and irrigation, livestock watering in agriculture and boating in recreation, or for industrial activities such as paper and pulp production. It is important that drinking water is kept, safe, clean and reliable [2]. Water is referred to as a global solvent because it can dissolve more substances than any other liquid; the nature of the solvents allows water to contain both beneficial and harmful substances [3]. The community water systems infections may lead to outbreaks of diseases that are likely to cause the disease in large number of consumers $[4,5]$. Research interest in drinking water contamination by intestinal protozoa has increased significantly over the last three decades, and a number of human parasitic infections are transmitted through the water-borne pathway [6]. Waterborne parasites are primary parasites that are spread everywhere and affect humans, domestic animals and wildlife around the world. Minimum of 325 water related outbreaks of parasitic protozoan diseases have been reported around worldwide [7]. There are many factors that contribute to the spread of diseases, including heavy rains, water, and agricultural residues, which will transport the parasite to surface water through soil [8]. Therefore, contaminated household water tanks are one of the main causes of intestinal diseases transmitted in developing countries [9].Waterborne diseases worldwide are among the most common diseases that kill children under the age of five, and more people die each year from unsafe water than from all forms of violence, including war [10]. There are four main categories of water-related diseases: waterborne (orally), water-washed, and water-related insects. Many water-related diseases are the result of poor quality water that is used for washing, drinking, and other uses [11]. The aim of this study was to define an important reference for all researchers and authors who plan to study the field of water-borne parasites more comprehensively in the future

\footnotetext{
${ }^{*}$ Corresponding author: Hadi Hind
} 


\section{Waterborne parasites in Iraq}

In Iraq there are many areas that do not have sewage systems with toilet discharge under the houses, and there are also many areas that empty sewage discharge into rivers [12]. Hadi and Faraj [2] in their study for distribution of intestinal parasites in drinking water in some regions in Baghdad province, Iraq (Hi-Al-Maalf, Hi-Al-Jehad, Al-Dura, AlShabab and Al-Baya'a), they found the total contamination rate in sewage water was $60 \%$ with these parasites: Ascaris lumbericoides, Entamoeba histolytica, Fasciola sp. and Strongyloides stercoralis, in tap water was 17.2\% . Hussein [13]. who study the prevalence and associated risk factors for Giardia lamblia infection among children with acute diarrhea in Thi- Qar, who explained that acute diarrhea is a major public health problem in Iraq, drinking raw or municipal water, hot seasons, and living with four or more children staying at home were significantly associated with lamblia giardiasis infection ( $p$ <.05); the infection rate of children with 33.3\% of Giardia lamblia . [14] in their study for pathogenic intestinal parasites in fresh water from the Al-Kadhimiya and Al- Gherai'at banks of the Tigris river in Baghdad provinces, Iraq they found Taenia sp., Ascaris lumbricoides, Schistosoma haematobium, Polymorphus sp.,Trichuris sp., Trichomonus vaginalis, Chilomastix sp., Iodamoeba butschlii, Entamoeba histolytica , Strongyloides stericorailis, Naegleriae sp., Coccidia sp., Acanthamoeba sp., Giardia sp. and Blantidium sp. Cryptosporidium parvum, Cryptosporidium muris, These results indicate freshwater contamination by sewage discharge and its consequences for human health, especially for swimming. Later, [15] they recorded Entamoeba coli, Giardia lamblia, Balantidium coli, Entamoeba histolytica, one helminth Hymenolips nana and Cryptosporidium sp. In rivers, reservoirs, and wells water in three areas (Abi-Gharaq, Al-Kefel and Al-Neil) in suburban of Babylon. [16] who study the Isolation and Identification of Cryptosporidium sp. through reverse osmosis system of tap water in Baghdad governorate. Two staining techniques were applied with zeal nelson stain and direct smear that showed oocyst of Cryptospordium sp and worm eggs, Ascaris lumbrecoides. These findings suggest the total contamination rate with intestinal parasites in tap water were $96.6 \%$ this high rate, refers to filtrate tap water by reverse osmosis system was helpful to block or reduce pollution of drinking water, in order to reduce risks to public health; it is therefore recommended to apply this method in water purification distribution of Cryptosporidium sp. were recorded the highest contamination rate in filtrate tap water samples, that due to potential temperatures of these protozoa as $\left(20-30{ }^{\circ} \mathrm{C}\right)$. In the same year [17] explained intestinal parasitic diarrhea among children in Baghdad governorate, Giardia lamblia has been shown to be the most prevalent parasite with an incidence of $45.54 \%$ followed by Entamoeba histolytica, Enterobius vermicularis, Hymenolepis nana, Trichuris trichiura, and Ascaris lumbricoides , As well as [18] in their study common causes of diarrhea disease among children under five years of age in some Iraqi governorates of Diyala, Haila ,Karbala, and Najaf, they found the prevalence of Giardiasis among Diyala governorate at p. value (0.001) as well as the large difference between Entamaebea histolytica among Karbala governorate at p. value (0.001), among other pathogens in our study governorates. Also [19] in their study for Prevalence of intestinal parasites found in different five areas that flow into Al-Razazza Lake, Iraq. They found the pollution of fresh water with 12 genus and species of parasites and protozoa: Cryptosporidium sp. was recorded the highest contamination rate with an incidence rate of $45.54 \%$, followed by Coleps hirtus, Ascaris lumbricoides, Giardia lamblia, Entamoeba coli, Hymenolepis nana, Entamoeba histolytica, Balantidium coli, Toxocara canis , Nyctotherus ovalis , Strongyloides sp. and Rhabditae larvae These study were similar to a previous study in the governorate of Babylon and the emergence of six types of common parasites are: Entamoeba coli , Giardia lamblia, Balantidium coli, Hymenolips nana , Cryptosporidium sp. and Entamoeba histolytica were repeated with the study of [15] in drinking water of Babylon governorate, which exposed a danger to public health. As well as [20] in their study related to the prevalence of Entamoeba histolytica/dispar and Giardia lamblia between the population of the eighteen governorates of Iraq, using the available surveillance database taken from the Ministry of Health, and they found E. histolytica/dispar the most prevalent parasite followed by G. lamblia. But disagreed with the results of [21] who indicated that the incidence of Giardia lamblia was significantly higher than the incidence of E. histolytica/dispar. Differences in the prevalence of these intestinal parasites between studies may due to many factors, including environmental, socio-economic, nutritional, and demographic as well as geographical conditions, and health-related behavior.

Baqer et al., [22] in their study for detection of water-borne parasites in drinking water of Baghdad province, Iraq. findings suggest the presence of parasites in the river and drinking water of Al-Rashid and Al-Wahdaa , Cryptosporidium oocyst which was established in river water samples are more than those in drinking water. Cryptosporidium oocyst in drinking water existed as it is resistant to environmental conditions and penetrates the physical barriers to water treatment to its small size. Moreover, it is resistant to many disinfectants used in water purification [23]. This study also found Acanthomoeba and Naegleria cysts existent in each months for Al-Rashid and Al-Wahdaa. Recently, [24].Who found five genera and pathogenic parasites in river water in Diyala governorate: Cryptosporidium sp., Acanthamoeba sp. , Entamoeba coli ,Rabditae larva and Strongyloides sp. 


\section{Conclusion}

The current study reviewed waterborne parasites in Iraq and an important reference for all researchers and authors who plan to study this field more comprehensively in the future. Our study revealed many intestinal parasites that transmitted by sewage water can lead to cause diseases in both human and animals. Protozoa that causes disease as Cryptosporidium sp., E. histolytica and Giardia Lamblia were more prevalence in fresh and tap water in some provinces of Iraq.

\section{Compliance with ethical standards}

\section{Acknowledgments}

Many thanks to all the Profs and Researchers who sent their papers and reserches that deals with the water born parasites directly or by emails or via Research gate. We would appreciate for Asst. Prof. Dr. Hussein Jebur (Department of Agricultural Machines and Equipment, University of Baghdad, Agricultural College) to review and publication the paper.

\section{Disclosure of conflict of interest}

There was no conflict of interest in this study.

\section{References}

[1] Kleiner SM. (1999). Water: an essential but overlooked nutrient. J Am Diet Assoc, 99(2), 200-206.

[2] Hadi AM and Faraj AA. (2008). Distribution of intestinal parasites in drinking water in some regions in Baghdad. AL-Qadisiya Journal of Vet. Med. Sci., 7(2), 33-37.

[3] World Health Organization (WHO). (2004). Guidelines for drinking water quality. 3rd edition, Geneva, 121-144.

[4] Pink DH. (2006). Investing in Tomorrow's Liquid Gold.

[5] West L. (2006). World Water Day: A Billion people worldwide lack safe drinkingwater.

[6] Lallo MA. (2012). Deforestation and Water Borne Parasitic Zoonoses, Deforestation Around the World, Moutinho, P., ed. (InTech).

[7] Kramer MH, Quade G, Hartemann P and Exner M. (2001). Waterborne diseases in Europe-1986-96. Journal of the American Water Works Association, 93, 48-53.

[8] Mac Kenzie R, Hoxie N J, Proctor ME, Stephen Gradus M, Blair KA, Peterson DE, Kazmierczak JJ, Addiss DG, Fox K R, Rose JB and Davis JP. (1994). A massive outbreak in Milwaukee of Cryptosporidium infection transmitted through the public water supply. New England Journal of Medicine, 331(3), 161-7.

[9] Molbak KN, Hojlyng S, Jepsen K and Gaarslev. (1989). Bacterial contamination of stored water and stored food: a potential source of diarrhoea in West Africa. Epidemiological Infection, 102, 309-316.

[10] World Health Organization (WHO). (2002). World Health Report: Reducing Risks, Promoting Healthy Life. France, 280.

[11] Acheson ED. (1992). Health problems in Iraq.BMJ, 304(6825), 455- 456.

[12] Al-Tammimi KE. (1999). Study in the epidemiology of Ascaris lumbercoides in Al-Museab and the effect of alcoholic extract of Allium sativum, Artimesia herba-aiba and piprazine sulphate.

[13] Hussein TK. (2010). Prevalence and related risk factors for Giardia lamblia infection among children with acute diarrhea in Thi- Qar southern Iraq. Thi-Qar Medical Journal (TQMJ), 4(4), 68-74.

[14] Hadi AM and Makawi ZA. (2013). Pathogenic intestinal parasites found in fresh water of the Tigris Riveri. Online Journal of Veterinary Research, 17(11), 608-619.

[15] Al-Dulaimi FH, Al-Hamairy AK, Shlash SA and Al-Hussaini FM. (2013). Investigation of Parasites in Drinking Water Sources of Three Suburban in Babylon Province. Journal of Babylon University. Pure and Applied Sciences, 21(3), 812-818. 
[16] Hadi AM. (2014). Isolation and Identification of Cryptosporidium sp. by Reverse Osmosis System of Tap water in Baghdad. J. Baghdad for Sci., 11(2), 894-899.

[17] AL-Kubaisy W, AL-Talib H, Al-khateeb A and Shanshal MM. (2014). Intestinal Parasitic Diarrhea among Children in Baghdad- Iraq. Tropical Biomedicine, 31(3), 499-506.

[18] Karem KK and Bara MK. (2016). Epidemiological study for common causes of diarrhea disease among children under 5 years of age in some Iraqi province. Karbala journal of pharmaceutical sciences, 11, 124-130.

[19] Hadi AM, Makawi ZA and Hadi HD. (2017). Prevelance of intestinal parasites found in Al-Razazza Lake, Iraq. J. Bio. \& Env. Sci., 11(5), 329-334.

[20] Al Saqur IM, Al-Warid HS and Albahadely HS. (2017). The prevalence of Giardia lamblia and Entamoeba histolytica/dispar among Iraqi provinces Karbala International Journal of Modern Science, 3, 93-96.

[21] Al-Warid HS. (2011). Prevalence of Gairdia lamblia and Entamoeba histolytic/Entamoeba dispar infections among children in ALShulaa and AL-khadimyaeBaghdad-Iraq. J. Univ. Anbar Pur Sci., 5 6e10.

[22] Baqer NN, Hammood AH, Hassan KF and Al-deen Hassan ES. (2018). Detection of water-brone parasites in drinking water of Baghdad- Iraq. Afr., J. Infect. Dis., 12(2), 1-6.

[23] Moore AG, Vesey G, Champion A, Scandizzo P, Deere D, Veal D and Williams KL. (1998). Viable Cryptosporidium parvum oocysts exposed to chlorine or other oxidizing conditions may lack identifying epitopes. International Journal for Parasitology, 28(8), 1205-12012.

[24] Makawi ZA. (2018). Prevalence of pathogenic parasites in river water in Diyala province. International Journal of Advanced Biological Research, 8 (2), 264-267.

\section{How to cite this article}

Hadi H, Hadi A and Jassim S. (2020). A review study of waterborne parasites in Iraq. GSC Biological and Pharmaceutical Sciences, 10(3), 22-26. 